\title{
Le vœu non acquitté : une originalité de la piété
} romaine

John Scheid

\section{OpenEdition}

\section{Journals}

Édition électronique

URL : http://journals.openedition.org/span/1627

DOI : $10.4000 /$ span. 1627

ISSN : 2268-1558

Éditeur

École pratique des hautes études. Sciences humaines

\section{Édition imprimée}

Date de publication : 1 janvier 2014

Pagination : 33-38.

ISBN : 9782909036434

ISSN : 0294-7080

\section{Référence électronique}

John Scheid, «Le vœu non acquitté : une originalité de la piété romaine », Systèmes de pensée en Afrique noire [En ligne], 19 | 2014, mis en ligne le 04 février 2020, consulté le 11 février 2020. URL http://journals.openedition.org/span/1627 ; DOI : 10.4000/span.1627 


\title{
Le vœu non acquitté : une originalité de la piété romaine
}

\author{
John Scheid \\ Historien, \\ Professeur au Collège de France
}

Au moment où le Centre Louis Gernet travaillait sur "La cuisine du sacrifice ${ }^{1}$ ", et où je fus sensibilisé aux questions sacrificielles, j'entendis, au séminaire de Jean-Pierre Vernant, un exposé de Michel Cartry sur le sacrifice en Afrique. Il me fit découvrir l'aspect très formel de ces rites, et ses recherches sont toujours restées pour moi une référence, une incitation à approfondir et un point de comparaison efficace. En souvenir de cette rencontre je voudrais présenter, en mémoire de l'incomparable spécialiste de l'étude rituelle que fut M. Cartry, ce complément aux recherches sur les vœux qui sont étroitement liés aux activités sacrificielles des Romains.

Il y a quelques années, j'ai attiré, après d'autres, l'attention sur l'originalité des pratiques votives des Romains'. Conclus sous forme contractuelle, c'est-à-dire conditionnelle, entre le célébrant et une divinité, les vœux romains ne sont acquittés que si le partenaire divin accomplit sa part du contrat : "da ut dem », et non « do ut des $»$. J'ai rassemblé quelques exemples de vœux qui n'étaient pas acquittés par les autorités romaines, par exemple lorsqu'éclatèrent les Guerres daciques de 101 et de 105 après notre ère. Et la lecture précise de certaines inscriptions émanant de la communauté palmyrénienne de Rome met en évidence que le vœu à la romaine ne pouvait pas être traduit en araméen : apparemment le contrat conditionnel - au demeurant par-

\footnotetext{
${ }^{1}$ Séminaire qui donna lieu à la publication de l'ouvrage La Cuisine du sacrifice en pays grec par M. Detienne \& J.P. Vernant, 1980

${ }^{2}$ Scheid, 1989, 1998.

${ }^{3}$ Scheid, 1989.
} 
${ }^{4}$ Scheid, 2005.

${ }^{5}$ Tite Live, Histoire romaine, 3,22,2

6 Tite Live, Histoire romaine, $3,15,4 ; 4.18$ 11.

7 Tite Live, Histoire romaine, $3,18,8$

${ }^{8} \mathrm{H}$. Versnel, 1975 ; Rüpke, 1990. faitement possible quand les mêmes divinités étaient considérées comme des divinités romaines - ne correspondait pas aux normes religieuses palmyréniennes ${ }^{4}$.

$\grave{A}$ ces documents je voudrais en ajouter deux autres, qui complètent et soutiennent les témoignages déjà invoqués. Dans la mesure où les Romains ne voyaient pas l'utilité de rappeler le défaut de l'assistance divine, il nous reste peu de témoignages du non-acquittement des vœux caducs. En 101 et 105, l'information provient des protocoles d'un collège sacerdotal public qui résumait toutes ses actions et donc également le non-acquittement éventuels des vœux prononcés. Peut-être l'initiative était-elle aussi destinée à révéler implicitement l'état de guerre qui se profilait à l'horizon. Mais pour l'heure, ce sont les seuls exemples explicites que j'ai pu recueillir. Désormais on pourra y ajouter les cas suivants.

Le premier exemple que je commenterai remonte à l'année 459 avant notre ère. Il est donné par Tite Live ${ }^{5}$ :

"Le recensement eut lieu cette année-là; mais à cause de la prise du Capitole et de la mort du consul, le scrupule religieux ne permit pas le lustrum qui le termine."

Le Capitole venait d'être occupé par des esclaves révoltés conduits par Appius Herdonius ${ }^{6}$. Le consul Publius Valerius Publicola fut tué lors de l'assaut du Capitole qui suivit cette occupation?. Ces événements appartiennent à l'histoire mythique de Rome. Mais cela ne doit pas nous occuper ici. Il nous suffira de constater comment Tite Live et ses sources racontent ces événements.

Pour comprendre les raisons de l'absence du lustrum conclusif du recensement, il faut évidemment comprendre le sens du terme lustrum.

Ce terme a toujours posé des problèmes aux historiens et aux traducteurs. Dans l'édition de la Collection des Universités de France, Gaston Baillet traduit le passage par "la religion ne permit pas la purification qui le termine". Or un lustrum n'est pas une purification ${ }^{8}$, comme Henk Versnel et Jörg Rüpke l'ont démontré. Lustrare et lustrum, 
qui ont un lien avec luceo, "éclairer ", signifient avant tout "parcourir, faire le tour de ", mais ils sont régulièrement traduits pas "purifier ". Nous n'allons pas examiner ici les raisons de cette traduction, mais c'est une donnée irritante des études rituelles sur laquelle il faudra revenir un jour de façon générale. Même si dans beaucoup de témoignages, l'interprétation est forcée, il est possible que dans certains contextes, il puisse s'agir de purifications. Dans le cas présent nous connaissons toutefois le rite, et il n'y a aucune raison de purifier le peuple une fois qu'il est constitué selon ses composantes.

Après avoir accompli les opérations du recensement du peuple et les autres activités liées à leur charge, les censeurs acquittaient, s'il y avait lieu, les voux prononcés cinq ans plus tôt par leurs prédécesseurs et formulaient à leur tour des voeux pour la période quinquennale sur laquelle portait leur censure. Une anecdote conservée par Valère Maxime concerne la modification d'un passage de la formule votive du lustrum par Scipion Émilien ${ }^{9}$ :

"Ne Africanus quidem posterior nos de se tacere patitur. qui censor, cum lustrum conderet inque solitaurilium sacrificio scriba ex publicis tabulis sollemne ei precationis carmen praeiret, quo di immortales ut populi Romani res meliores amplioresque facerent rogabantur, "satis" inquit "bonae et magnae sunt : itaque precor ut eas perpetuo incolumes seruent", ac protinus in publicis tabulis ad hunc modum carmen emendari iussit. qua uotorum uerecundia deinceps censores in condendis lustris usi sunt. "

Malgré la brièveté de la citation, il en ressort qu'il ne s'agissait pas de pureté et de purification, mais de l'intégrité et de l'état du peuple. Le nom lustrum provenait du fait que le sacrifiant promenait un verrat, un bélier et un taureau autour du groupe humain ou de la chose à constituer, à protéger contre toute attaque extérieure. Ensuite, ces victimes étaient offertes à Mars ${ }^{10}$.

Dans le témoignage qui nous retient, les censeurs n'ont pas acquitté le voeu formulé par les censeurs précédents. Ils l'ont fait, comme l'écrit Tite Live, par scrupule religieux (religione). Or l'historien donne les raisons de ce scrupule : le peuple romain n'était pas du tout dans le même état ou encore meilleur que cinq ans auparavant. Le
${ }^{9}$ Maxime Valère, Faits et dits mémorables, $4,1,10$. Voir aussi l'anecdote concernant la formulation des vœux lors du census de 14 ap. n. è. chez Suétone, Divin Auguste : 97.

10 Pour la description, voir Georges Dumézil, 1987 : 242 suiv. : Rupke, $1990: 144$ suiv. 
Capitole avait en effet été occupé par des esclaves insurgés et lors de l'assaut qui fut mené contre les insurgés, l'un des consuls avait été tué. Le dieu Mars n'avait donc pas défendu les intérêts du Peuple romain comme il l'aurait dû, et par conséquent le contrat votif ne fut pas honoré. Car le scrupule religieux interdisait de considérer comme accompli le service demandé au dieu. Nous pouvons considérer que, au moins dans l'historiographie, c'était là une façon spectaculaire de dénoncer une calamité politique et sociale.

Ce témoignage qui peut être inséré dans la série des vœux non acquittés concerne la religion publique. Nous pouvons nous demander si cette façon de traiter les divinités ne se rencontrait que dans le culte public. Est-ce qu'il y en a des exemples dans les cultes privés?

J'ai rencontré dans mes lectures le passage suivant des Bucoliques de Virgile" :

"Oủ portes-tu tes pas, Méris? Vas-tu à la ville, où ce chemin conduit?

- O Lycidas, n'avons-nous tant vécu pour voir (ce que nous n'aurions jamais craint) un étranger devenir le propriétaire de notre champ et nous dire : "Ceci est à moi; quittez le pays, anciens colons" Maintenant vaincus et tristes, jouets de la Fortune qui bouleverse tout, nous envoyons ces chevreaux au ravisseur : puisse ce don mal tourner pour lui."

"Quo te, Moeri, pedes? an, quo uia ducit, in urbem?

M. O Lycida, uiui peruenimus, aduena nostri (quod numquam ueriti sumus) ut possessor agelli diceret "haec mea sunt; ueteres migrate coloni". Nunc uicti tristes, quoniam Fors omnia uersat hos illi (quod nec uertat bene) mittimus haedos. "(Trad. Maurice Rat)

Virgile mentionne deux bergers qui sont abattus parce qu'eux-mêmes ou leurs patrons ont perdu leurs terres, et que la fortune leur est défavorable. J'aurais tendance à écrire Fors avec une majuscule comme le font certains éditeurs (Maurice Rat par exemple), car Virgile me paraît faire allusion à la déesse Fors Fortuna, à qui le vœu initial était adressé. La déesse de la chance imprévisible était une divinité volontiers invoquée par les esclaves. Le berger constate donc que son contrat votif est rompu et il offre les victimes promises, non à Fors mais à son nouveau maître. Fors, qui ${ }^{11}$ Virgile, Ecl. 9, 1.6:L. bouleverse tout, s'est montrée indifférente au vou et ne 
mérite donc pas les victimes, et le contractant malheureux les conduit au nouveau maitre, en souhaitant que pour lui aussi tout tourne mal.

Cet exemple poétique illustre donc à sa manière la pratique rituelle courante, qui consiste à ne pas acquitter les vœux non exaucés. L'intérêt de ce témoignage réside dans le fait qu'il s'applique à la religion domestique, privée, et démontre qu'il s'agit là d'un comportement religieux général des Romains. Le refus d'acquitter des vœux non exaucés ne se pratiquait pas seulement sur le forum, dans la religion publique.

Cette manière de contracter avec les dieux est un trait typique de la piété romaine qui considère les divinités comme des partenaires terrestres avec lesquels l'individu ou la collectivité se conduisent de la même manière qu'avec les humains. Un tel comportement heurtait apparemment les règles de piété palmyréniennes, et ne pouvaient pas être exprimées dans leurs dédicaces ${ }^{12}$, et nous savons qu'il en va de même dans le carholicisme, pour les vœux faits à Dieu. Avec les saints, les fidèles peuvent se conduire de façon très "romaine ", mais avec Dieu une distinction est faite entre le vou et la grâce accordée ou non, et souvent l'acquittement précède la satisfaction de la demande. L'historien moderne a donc intérêt à ne pas se laisser déterminer, consciemment ou non, par les conceptions actuelles de la relation avec les puissances divines, et replacer dans leur contexte les rites qu'il rencontre dans les textes antiques. En cela il se conformera à l'enseignement que nous a laissé Michel Cartry. 


\section{Références bibliographiques}

Detienne, M. \& Vernant, J.P.

1980 La Cuisine du sacrifice en pays grec, Paris, Gallimard, coll. "Bibliothèque des histoires" ".

Dumézil, G.

1987 La Religion romaine archaique, Paris.

Rüpke, J.

1990 Domi militiae. Die religiöse Konstruktion des Krieges in Rom, Stuttgart, pp. 144. 146.

Scheid, J.

2006 "Manger avec les dieux. Partage sacrificiel et commensalité dans la Rome antique ", in S. Georgoudi, R. Koch-Piettre \& F. Schmidt (dir.), La Cuisine et l'autel. Les sacrifices en questions dans les sociétés de la Méditerranée ancienne, Tournai, (Bibliothèque de l'Ecole des Hautes Etudes Sciences Religieuses, vol. 124), pp. 273-287.

2005 "Épigraphie et identité religieuse, ou l'art de la traduction ", in J. Demougin \& C. Hoët-Van Cauwenbergue, Le Monde romain à travers l'épigraphie : méthodes et pratiques, Lille, Université Charles de Gaulle Lille 3 , pp. 217-229.

1989-90 "Hoc anno immolatum non est. Les aléas de la voti sponsio ", Scienze dell'Antichità 3-4, pp. 775-783.

1998 "Les incertitudes de la uoti sponsio. Observations en marge du uer sacrum de 217 av. J.-C. ", in M. Humbert \& Y. Thomas (dir.), Mélanges à la mémoire d'A. Magdelain, Paris, LGDJ, éd. Panthéon-Assas, pp. 417-425.

Suétone
[s. d.]
Divin Auguste, 97.

Tite Live

[s. d.] Histoire romaine 3, 22, 2 : Consules creati Q. Fabius Vibulanus tertium et L. Cornelius Maluginensis. Census actus eo anno: lustrum propter Capitolium captum, consulem occisum condi religiosum fuit (traduction de la Collection des Universités de France, modifiée).

Valère, $\mathrm{M}$.

2003 Faits et dits mémorables, [éd. et trad. fr. Robert Combès], Paris, Les Belles Lettres (Collection des universités de France), livres I-VI, 2 tomes, ( $2^{\mathrm{e}}$ tirage)

Versnel, H.

1975 "Sacrificium lustrale : the death of Mettius Fufetius (Livy 1, 28) : Studies in Roman lustration-ritual ", MNIR, 37, 97-115.

Virgile

[s. d.] Bucoliques, Ecl. 9, 1-6. 